\title{
A identidade divina em fragmentos do Êxodo
}

\author{
Valdenildo dos Santos*
}

\section{Resumo}

Neste trabalho, ao falar-se de uma divindade judaico-cristã, não se pretende dar ênfase ao caráter epistêmico, o qual depende do crer ser ou crer não ser, mas, pretende verificar o seu percurso enquanto ator e destinador social, presente no nível da manifestação por meio de parte da narrativa vétero-testamentária, contida no livro do Êxodo. Neste exame de seu papel actorial e actancial, como sujeito presente no enunciado bíblico na forma de Yaweh (Jeová) e "O Eu Sou o que Sou", procura-se mostrar que Jeová investe Moisés da competência para realizar o programa narrativo da libertação do povo hebreu da escravidão egípcia. Enquanto o Eu Sou O Que Sou, revela-se como divindade absoluta de identidade consumada por meio da isotopia da unicidade, explorada in texto, a análise imanente do fragmento textual em estudo, característica principal da semiótica da Escola de Paris, mostra a identidade humana, em oposição, em processo de construção. Conclui-se, assim que a semiótica se transforma em importante ferramenta para a leitura de enunciados de caráter verbal, no caso, de forma objetiva, mesmo que este tenha relevância religiosa como objeto da fé no bojo de religiões ao redor do mundo levadas a interpretações variadas e subjetivas.

Palavras-chaves: Identidade; Divindade; Judaísmo; Cristianismo; Semiótica.

* Possui graduação em Letras Português Inglês pela USC, Universidade do Sagrado Coração (1992), mestrado em Comunicação e Poéticas Visuais pela UNESP, Universidade Estadual Paulista Júlio de Mesquita Filho (1996) e doutorado em Letras pela UNESP, Universidade Estadual Paulista Júlio de Mesquita Filho (2001), com bolsa Sanduíche CNPq de pesquisa na UNC, University of North Carolina, Chapel Hill, Estados Unidos. Morou nos Estados Unidos, Carolina do Norte e Virgínia durante oito anos (2003 a 2011). Atualmente é professor adjunto II da Universidade Federal de Mato Grosso do Sul, Campus Três Lagoas. É professor do Mestrado Profissionalizante PROFLETRAS. É Líder do Grupo de Ensino e Aprendizado de Línguas e Semiótica (GEALLES), linhas de pesquisa em Linguística (leitura crítica via semiótica) e Letras (ensino de línguas e produção de material didático). E-mail: lavsotnas@hotmail.com 


\title{
The divine identity in exodus fragments
}

\begin{abstract}
In this paper, taking into consideration that when we speak of a Jewish-Christian deity we do not intend to emphasize epistemic character, which depends on believing it to be or not to be, but to verify its path as an actor and social addresser inserted in the level of manifestation through part of the old testamentary narrative contained in the book of Exodus. In this examination of its actorial and actantial role as a subject in this biblical passage that identify himself as Yahweh (Jehovah) and "The I Am What I Am", showing that as Jehovah, He invests Moses of the competence to conduct the narrative program of deliverance of the Hebrew people from Egyptian slavery. While The I Am What I Am He reveals himself as absolute deity with his identity consummated by the isotopy of circularity explored in text, through the immanent analysis of the textual fragment in study, the major feature of the semiotics of the School of Paris, it shows the human identity, in contrast of the divinity identity, in a process of construction. We conclude therefore that semiotics becomes an important tool for reading verbal text objectively, even though it has religious relevance as an object of faith within religions around the world leading to subjectivity.
\end{abstract}

Key-Words: Identity; Divinity; Judaism; Christianism; Semiotics.

\section{Introdução}

O presente artigo tem por objetivo principal apresentar uma leitura objetiva do texto bíblico ao revelar a identidade divina e, em consequência, a identidade humana por meio de alguns versículos do Êxodo, em que está presente a passagem do povo hebreu do cativeiro egípcio para a terra de $\mathrm{Ca}$ naã em busca da libertação, configurando-se assim um deslocamento espacial.

Afirma-se, por meio do percurso narrativo da divindade judaico-cristã, que a sua unicidade surge em sua aparição ao sujeito operador Moisés, como o "Eu Sou o Que Sou", em primeiro plano, não revelando o seu nome, mas, mostrando-se, conforme veremos pela análise, como divindade absoluta que nasce e se consome em si mesma. Num segundo plano, na delegação da missão a ser cumprida por Moisés, procura, como sujeito destinador, investi-lo da competência para realizar o programa da libertação de seu povo, resgatando a forma com que se identificava a este na pessoa de Jeová, o Senhor (Iahweh), o Deus de Abraão, Isaque e Jacó, patriarcas importantes e considerados no interior da cultura judia, no sentido de fazer Moisés e, por extensão o próprio povo judeu, que os guarda em memória viva como heróis em sua história passadista, acreditarem que era o enviado.

Deus revela-se, assim, como o único ser a ter uma identidade consu- 
mada em oposição à identidade humana que vive uma busca constante de valores, uma ideologia bem definida por Greimas (2012, p. 252). Aos seres humanos, mortais cabem apenas traços identitários. Essa isotopia ${ }^{1}$ (BARROS, 1990 , p. 87) da unicidade que mostra a identidade consumada da divindade judaico-cristã é a base para reflexões mais profundas sobre a identidade humana, limitada e em construção, nesta perspectiva analítica.

A importância desse artigo decorre de metodologia criteriosa e paulatina e dos enfoques que a análise semiótica aplica a fim de extrair interpretações coerentes e minuciosas do texto em estudo que, por sua vez, não devem estar baseadas, necessariamente, em alguma (s) corrente(s) de cunho especulativo ou religioso.

Para uma análise de teor semiótico, são consideradas as diferentes etapas na realização discursiva, que consideram desde a superficialidade de um discurso até as suas estruturas mais específicas e fundamentais. Desta forma, como sujeitos interpretativos, a priori, fazemos uma abordagem mais estrutural do texto e avaliamos aspectos da sintaxe narrativa, semântica narrativa e a semântica discursiva (coerência textual, estruturas fundamentais e nível profundo).

A posteriori descrevemos as observações que corroboram a isotopia da circularidade (unicidade) presente nas palavras do destinador divino no fragmento textual do Exxodo. Primamos, todavia, por uma abordagem centrada na objetividade textual.

\section{Por uma leitura objetiva do texto}

O bojo analítico da semiótica nos propõe interpretar os textos consoantes a uma metodologia criteriosa e minuciosa. No discorrer do estudo do nosso corpus, empregamos conceitos e aspectos dessa metodologia (sintaxe narrativa, semântica narrativa e a semântica discursiva) que nos nortearam a leituras mais precisas e ricas do texto, sem nos atermos ao contexto. $\mathrm{O}$ valor da postura semiótica, portanto, incorre nesse aspecto interno do texto e seu percurso gerativo do sentido.

Greimas e Courtés afirmam que num mesmo discurso há uma superposição de isotopias diferentes. É o que chamam de pluri-isotopia, que é introduzida por conectores de isotopias e está ligada aos fenômenos de

Reiteração de quaisquer unidades semânticas (repetição de temas ou recorrência de figuras) no discurso, o que assegura sua linha sintagmática e sua coerência semântica. 
polissemia: "uma figura plurissêmica, que propõe virtualmente vários percursos figurativos" e que pode dar lugar "a leituras diferentes e simultâneas" (GREIMAS; COURTÉS, 2012, p. 371). Isso é possível, no entanto, se as unidades figurativas no nível da manifestação não forem contraditórias. Assim, essas figuras convergem para temas que desencadeiam pluri-isotopias que, no nível profundo da significação, convergem para uma isotopia principal.

Roland Barthes (1989) não está equivocado ao defender as leituras plurais nos textos literários. Mas, é preciso entender que estas leituras possíveis surgem a partir dos programas narrativos de uso e que no final vão convergir para uma leitura principal que surge com o programa narrativo de base. Como dizem Greimas e Courtés (2012, p. 282), apesar dos textos "práticos", nos quais eles incluem as "receitas" culinárias ou os textos jurídicos que são considerados monoisotópicos conterem ambiguidades, é "no nível dos enunciados" que devem ser remediadas "propondo o contexto-discurso como o lugar de sua desambiguação".

Deve-se, ainda, excluir o que se chama de "senso poético" ou o "senso musical", que são as condições psicofisiológicas dos leitores, porque o enunciatário é um actante de acordo com o texto. Ele não é uma classe de atores individuais que não têm fim. Admite o semioticista lituano que um mesmo texto pode conter diversas isotopias de leitura (GREIMAS, 2012, p. 251). Por outro lado, o mesmo Greimas (2012, p. 282) contraria a posição de Barthes: "afirmar que existe uma leitura plural dos textos, isto é, que um texto dado oferece um número ilimitado de leituras, nos parece uma hipótese gratuita, tanto mais que é inverificável".

É possível ver no nível profundo da análise, portanto, por meio do quadrado semiótico proposto por Greimas (2012), a partir de um jogo de oposições, inspirado em Ferdinand de Saussure, que dizia que o sentido está nas diferenças, essa leitura principal do enunciado (SAUSSURE, 1984, p. 189-190).

Sob este prisma, as leituras plurais de Barthes podem ser equiparadas às pluri-isotopias de Greimas que aparecem ainda nos níveis anteriores ao nível profundo. Não se trata de Greimas estar certo e Barthes estar errado ou vice versa, mas de maneiras distintas de abordar-se determinadas questões. Assim, a ilusão referencial, por exemplo, de Barthes (1989, p. 189-190) seria como o efeito de sentido para Greimas, aquela primeira impressão que se tem daquilo que se acaba de ler ou ver (2012, p. 155). A objetividade do texto, aqui, é que nos interessa, embora se saiba que há pluri-isotopias, espécies de 
subtemas que, ao final da análise, convergem a um tema principal, como a isotopia da circularidade na fala da divindade judaico cristã, que pretendemos demonstrar, que leva à unicidade.

\section{Conceito de identidade: da semiótica à psicanálise.}

$\mathrm{Na}$ concepção semiótica a identidade é vista em oposição à alteridade segundo a definição clássica do "mesmo" e do "outro". Para Waldir Beividas, a identidade serve de parâmetro à avaliação da "mesmidade", mas, impede a auto-suficiência do semantismo de sua concepção: "Sempre haverá um traço sêmico da diferença a parametrar os eventuais traços sêmicos da identidade (de um objeto ou um sujeito) (2006, p. 136) ${ }^{2}$.

Ele parte do quadrado semiótico elaborado por Claude Zilberberg do "mesmo" como "idêntico" e do "outro" como "diferente" e faz a seguinte reformulação: "identidade" em oposição à "diferença" em que o eixo contraditório da "não-diferença" está para a "identificação" e o eixo contraditório da "não-identidade" está para a "diferenciação" (ZILBERBERG, 2006, p. 136). Com base nesta concepção, afirma que a identidade é modalizada por um forte "querer", isto é, um querer tônico-tensivo e a identificação traduz uma posição semântica do sujeito vetorizada para a busca de uma identidade (absoluta, mas impossível) com quem de direito (os pais e posteriormente seus delegados, na visão atorializada de S.Freud em relação aos filhos) (2006, p. 137).

Para Beividas (2006, p. 137) a identidade é como uma "paixão-limite, ponto de miragem patêmica do sujeito, mesmo se totalmente fundada numa posição epistêmica ilusória do / crer/ / ser/ + não / saber/ não / ser/", assim situada à identidade, numa área limite que continua como uma linha do horizonte. Neste caso, as situações humanas de vínculos sociais totalizantes ou de subjetividade em construção seriam de "interações intersubjetivas ou da dinâmica (libidinal) psíquica". Essas interações seriam distribuídas "na larga faixa de um percurso sobtensão entre o polo do "mesmo" e do "outro", no percurso complexo, matizado e fortemente modalizado, da Identificação ou das identificações".

Pelo exposto, Beividas (2006, p. 132) afirma que há um problema para definir-se a identidade de forma satisfatória quanto aos seus limites e

2 Disponível em http://www.fflch.usp.br/dl/waldirbeividas/publicacoes.htm, Acesso em: 28 jun.2012. 
extensão e, por isso, sugere um lócus teórico para que possa ser pensada do ponto de vista semiótico e psicanalítico. Chama a atenção para a problemática da criação desse lugar teórico, por conta da existência das duas teorias. Desta forma, coloca como hipótese de trabalho que "as proposições apresentadas tanto pela semiótica quanto pela psicanálise não atendem à sutileza semântica e a densidade estrutural do conceito de identidade".

A identidade divina aqui postulada é medida segundo a concepção tradicional da semiótica em oposição à identidade humana, afirmando-se que a divindade judaica apresenta uma identidade definida, consumada, diferentemente do que pensa Beividas (2006), absoluta, por tratar-se de um sujeito que se identifica a Moisés como o "Eu Sou o Que Sou". Diante deste discurso, desta assertiva, in texto, no nível da manifestação, o que se pode fazer é analisar e essa é uma tarefa do semioticista, mostrar que o Eu Sou o Que Sou começa e termina em si mesmo, ao passo que a identidade humana, esta sim, como cita Beividas o caso do filho que quer / parecer/ e /ser/ como o pai (2006, p. 140), está sempre em construção e, é claro, neste percurso o sujeito sofre oscilações no limiar da linha tensiva. É certo, todavia, que tanto um quanto o outro são dispostos à mesa para análise enquanto produtos da linguagem, enquanto existentes e presentes in texto, sem nos enveredar por questões de fé. Logo, deste ponto de vista, o que parece contrário, oposto, na verdade, se complementa, se assemelha, se identifica quando um procura refletir a imagem do outro.

Não se pretende, no entanto, aqui, traçar esse percurso tensivo do sujeito humano em busca da sua identidade, mas de mostrar a construção da identidade divina como única e exclusiva pelo seu caráter onipresente, onisciente e onipotente segundo a concepção lógica ${ }^{3}$ (JAPIASSÚ; MARCONDES, 2006, p. 140) com base na narrativa bíblica expressa por três versículos do capítulo três do livro do Êxodo como segue:

13 Então, disse Moisés a Deus: Eis que quando vier aos filhos de Israel e lhes disser: O Deus de vossos pais me enviou a vós; e eles me disserem: Qual é o seu nome? Que lhes direi?

14 E disse Deus a Moisés: Eu Sou o Que Sou. Disse mais: Assim dirás aos filhos de Israel: Eu Sou me enviou a vós. 3 Na lógica aristotélica a identidade tem o seu princípio nas três leis básicas do raciocínio
e expressa-se na fórmula "A" = "A", ou seja, todo objeto é igual a si mesmo. 
15 E Deus disse mais a Moisés: Assim dirás aos filhos de Israel: O Senhor, o Deus de vossos pais, o Deus de Abraão, o Deus de Isaque, o Deus de Jacó, me enviou a vós; este é meu nome eternamente, e este é meu memorial de geração a geração (BÍBLIA DE ESTUDO DEFESA DA FÉ, 2009, p. 102) ${ }^{4}$.

No plano interpretativo, a priori, como enfatizado anteriormente, faz-se aqui uma abordagem mais estrutural do texto, avaliando aspectos da sintaxe narrativa, semântica narrativa, semântica discursiva (coerência textual e estruturas fundamentais) e sintaxe profunda. A posteriori descrevem-se as observações que corroboram a isotopia designada na análise sob o termo circularidade (unicidade) presente nas palavras do narrador textual.

\section{Sintaxe Narrativa}

De posse do corpus em análise, pode-se definir e estabelecer sua descrição semiótica. Para fins de assimilação e ilustração recorre-se ao seguinte elenco de símbolos semióticos para desenvolver o estudo.

S1 é sujeito destinador, actante narrativo que determina os valores em jogo e que dota o destinatário-sujeito da competência modal necessária ao fazer (destinador- manipulador) e o sanciona, recompensando-o ou punindo-o pelas ações realizadas (destinador-julgador) (BARROS, 1990, p. 85). Portanto, no nosso caso, esse sujeito concerne à figura de Deus que não sanciona Moisés no corpus estabelecido, deixando essa sanção de caráter negativo (não entrar na terra prometida) na consideração total da narrativa.

S2 é sujeito destinatário e ao mesmo tempo operador, Moisés, actante narrativo manipulado pelo destinador, de quem recebe a competência modal necessária ao fazer e é por ele reconhecido, julgado e punido ou recompen-

Esta outra versão da Bíblia Judaica Completa trata assim a passagem: Mosheh disse a Deus: Quando eu aparecer diante do povo de yisra'el e lhes disser: "O Deus de seus ancestrais enviou-me a vocês". E eles me perguntarem "Qual é o nome dele" o que lhes direi? Deus disse a Mosheh: "Ehyeh Asher Ehyeh [Eu sou/serei o que sou/serei]" e acrescentou: "Eis o que você deve dizer ao povo de Yisra'el. Ehyeh [Eu sou ou Eu serei] enviou a vocês". Além disso, Deus disse a Mosheh: "Diga isso ao povo de Yisra'el: "Yud-hev-Van-herh [Adonai] o Deus de seus pais, o Deus de Avraham, o Deus de Yitz'chak e Ya'akov enviou-me a vocês". Este é o meu nome para sempre. Desejo ser lembrado dessa forma. Sh'mot [Êxodo], Capítulo 3, versos 11-21, página 134, Bíblia Judaica Completa, o Tanakh [AT] e a B'rit Hadashau [NT]. Tradução do original para o inglês de David H. Stern. Tradução para português de Rogério Porterla e Celso Fernandes. Editora Vida, 1998 (inglês) e 2019 (português). 
sado, segundo as ações que realizou (BARROS, 1990, p. 85). Pelo proposto, esse sujeito é representado por Moisés, que consideramos com base apenas no corpus apresentado como sujeito virtualizado.

S3 representa a quem realmente se direciona a proposta do sujeitodestinador. Isto é, a figura do povo israelita cujo programa narrativo está virtualizado, considerando-se os três versículos acima citados.

PN é a representação do programa narrativo e atua como sintagma elementar da narrativa, que integra estados e transformações, e que se define como um enunciado de fazer que rege um enunciado de estado (BARROS, 1990, p. 89). Observamos, portanto, que o PN primordial é a libertação do povo israelita.

OV é o objeto-valor determinado pelas aspirações e projetos do sujeito, por seus valores, em suma (BARROS, 1990, p. 88). Salta-nos a aspiração de Deus em instaurar em Moisés a crença para que este realize a missão.

O valor é o termo de uma categoria semântica, selecionada e investida em um objeto com o qual o sujeito mantenha relação, posto que, como afirma Barros (1990, p. 90), "é a relação com o sujeito que define o valor.

O símbolo de função é $\rightarrow$, igual à transformação, e nesta análise implica no enunciado de fazer.

Finalmente este símbolo $\cap$ quer dizer “junção" e diz respeito à relação que determina o estado, a situação do sujeito em relação a um objeto qualquer, conforme explica Barros (1990, p.19). Notoriamente, reflete o anseio de Deus para adquirir a fé de Moisés.

De posse desses termos e definições, podemos iniciar a nossa abordagem semiótica. A seguir está esboçado o fluxo do PN do S1

Figura 1. Percurso narrativo do S1.

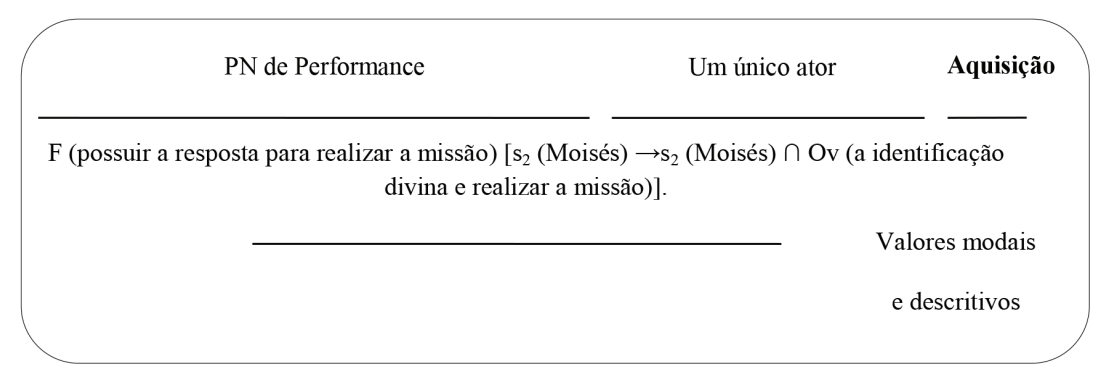


Alerta-se aqui, que o PN de Moisés (S2) assume uma configuração virtualizada, ao passo que inferimos, por pressuposição lógica, que esse PN é concretizado, se considerarmos a narrativa inteira do Exxodo. O PN do S2 apresenta o seguinte fluxo.

Figura 2. Percurso narrativo do s2

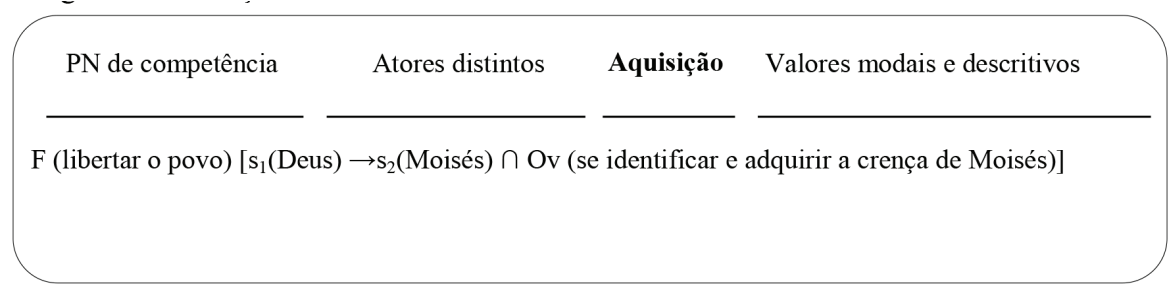

Enfatiza-se aqui que a identificação divina (=crença) é $\mathrm{Om}^{1}$ /objeto modal $/=\underline{\text { meio }}$; e a missão=libertar o povo de Israel, é /Objeto-Valor/ = fim almejado). Objeto modal =relação hipotáxica, conforme mostra Nícia Ribas D’Ávila em Renart e Chanteclerc (1990, p. 12).

Esmiuçando o PN de S1, percebemos que a transformação resulta numa junção entre o sujeito e o objeto-valor e, portanto, assume a tipicidade de um programa de aquisição, na dependência de um valor modal (objetomodal) por meio do qual Deus, ao conceder a resposta a Moisés visa, concomitantemente, afirmar a crença de Moisés para consigo. Como a relação narrativa ocorre, essencialmente, entre dois sujeitos - S1 (sujeito do fazer) e S2 (sujeito de estado) -, ela é transitiva. O critério tipológico é a competência, haja vista que S1 doa a resposta (outro valor modal $=\mathrm{Om}^{2}$ ) a S2 (sujeito de estado).

Quanto ao PN de S2, inferimos que se trata também de um programa de aquisição; S2 anseia o nome de S1 para realizar sua missão, porém, sua relação narrativa é reflexiva: S1 de posse da resposta de S2 se tornará apto a cumprir sua função. Abaixo segue um quadro comparativo para demonstrar as características dos programas narrativos de S1 e S2. 


\subsection{Caracterização do Programa Narrativo}

\begin{tabular}{|l|l|l|l|l|}
\hline & $\begin{array}{l}\text { NATUREZA } \\
\text { DA FUNÇÃO }\end{array}$ & $\begin{array}{l}\text { RELAÇÃO } \\
\text { NARRATIVA/ } \\
\text { DISCURSO }\end{array}$ & DENOMINAÇÃO & CRITÉRIO \\
\hline S1 & Aquisição & Transitiva & Crença/Libertação & Competência \\
\hline S2 & Aquisição & Reflexiva & $\begin{array}{l}\text { Conhecimento/Li- } \\
\text { bertação }\end{array}$ & Performance \\
\hline
\end{tabular}

Esses programas narrativos se organizam em percursos narrativos que segundo Barros (1990, p. 8), consiste numa "sequência de programas narrativos de tipos diferentes (de competência e de performance), relacionados por pressuposição simples".

Em virtude do caráter virtualizado do S2, dedica-se esta seção para o percurso narrativo do S1. Sendo o S1 o destinador, este pode ser destinador -manipulador ou destinador-julgador. Decerto, embasado no corpus, o S1 é um destinador-manipulador, pois não há sanção visível no trecho.

A manipulação meneada pelo $\mathrm{S} 1$ edifica-se em duas etapas. $\mathrm{Na}$ primeira, há a atribuição de competência, pois é vital que o sujeito-operador (S2) creia nos valores do destinador, ou por ele, determinados, objetivando que este se deixe manipular. Quando S1 declara seu nome, reforçando seu teor de unicidade e absolutismo, faze-o almejando sedimentar a crença de S2, quanto a sua existência e confortá-lo para a libertação do S3.

Num segundo plano, ocorre a manipulação propriamente dita, na doação dos valores modais (dever-fazer) expressa claramente nos trechos: “... Eis como responderás aos israelitas... Assim falarás aos israelitas...”. Com efeito, S1 concede a resposta a S2 para que este opere o papel por aquele delegado.

Nesse permeio, oportunamente, temos como tipicidade de manipulação mais evidente, a intimidação. $\mathrm{O}$ modo incisivo e redundante da resposta e a própria condição de divino do S1 são indicadores pontuais da intimidação que S1 lança a S2. Contudo, numa leitura mais visceral e pormenorizada, emerge, discretamente, a manipulação por tentação.

O S2 vislumbra o seu futuro como consequência do contrato fiduciário e a realização da missão demandada pelo S1. Cabe recordar, que esse 
último parecer está consubstanciado na pressuposição lógica com base em toda a narrativa do Êxodo.

Apesar da ofuscação por parte da condição de S1 como sujeito-manipulador, o vulto de sujeito-julgador está presente. Manifesta-se uma auto-sanção positiva, de Deus (S1) para consigo mesmo, ao enunciar "Eu Sou o Que Sou". Assim, S1 reafirma sua própria existência, dirimindo demais interpretações, bem como reconhece a si próprio como único e infinitamente temporal.

\subsection{Semântica narrativa}

Nessa seção, a vertente analítica se avoluma com o bojo da modalização que segundo Barros (1990, p. 88), refere-se à “determinação que modifica a relação do sujeito com os valores (modalização do ser) ou que qualifica a relação do sujeito com o seu fazer (modalização do fazer)". As duas formas de modalização ocorrem no nosso texto, explicitando outros aspectos que contribuem para uma abordagem mais proeminente.

No tocante à modalização do ser, saltam-nos as modalidades virtualizantes e as atualizantes, instaurando o sujeito. As modalidades virtualizantes presentes são o /querer- fazer/, porque S2 aspira conceder uma denominação do S1 ao S3 e /dever/-/fazer/, quando S1 ordena a S2 propagar ao S3 a resposta que ele proferiu. Quanto às modalidades atualizantes, há o / saber/-/fazer/ quando S2, após a obtenção da identificação de S1, saberá como proceder perante o S3.

$\mathrm{Na}$ esfera da modalização do ser, figura a modalização veridictória - um estado verdadeiro quando um sujeito diferente do sujeito modalizado o diz verdadeiro - o S1 demonstra-se parecer único na identidade divina de Javé (Senhor), mas, na imanência, constitui-se num ser verdadeiramente único no "Eu Sou o Que Sou". Na modalização do /querer/, S2 quer conhecer o nome de S1 a fim de confirmar seu amparo e dirimir sua insegurança ao passo que S1 quer sedimentar a crença de S2 para consigo e libertar o S3. Quanto ao /saber/, S2 detém o saber relacionado à identificação de S1; Ao/dever/, provido do conhecimento da identificação de S1, S2 deve cumprir sua missão; e ao /poder/, ao deter o apoio de S1 quando S2 está apto a libertar o S3. Vale enfocar que o objeto modalizador capital empregado pelo S1 para consolidar seu propósito é a voz. 


\section{Semântica discursiva}

Enveredando-nos numa observação mais exacerbada, o passo seguinte incorre na determinação das leituras possíveis do texto, as leituras plurais, ou seja, ocorrência de várias interpretações. Podemos identificar no texto, sobretudo, a isotopia temática que decorre da repetição de unidades semânticas abstratas, conduzindo a uma coerência textual. Essa isotopia se exibe nos termos "Sou", "Deus", e viabiliza a confecção do seguinte quadrado semiótico, incitando e aclarando as relações das oposições por contrariedade e por contradição.

Figura 3. Quadrado semiótico

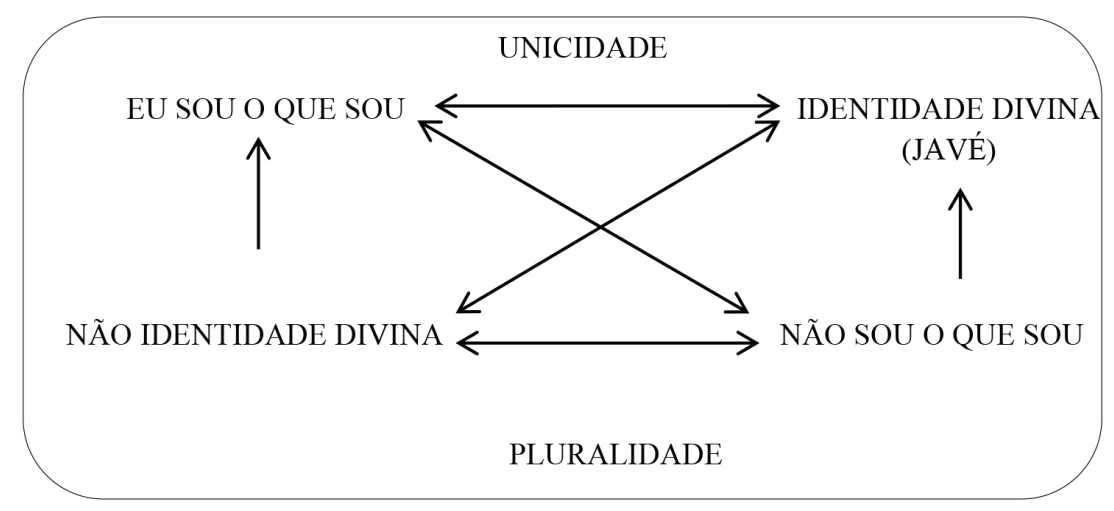

Pedagogicamente, as linhas uniformes com setas cruzadas conotam relações entre contraditórios; as setas verticalizadas e direcionadas ao alto simbolizam a relação entre complementares; as setas horizontalizadas referem-se à relação entre termos contrários. Com efeito, recorrendo a sequência lógica para o encontro da isotopia geral, que parte de pluralidade rumo à unicidade, tendo como termo intermediário, contraditório, se colocado no quadrado, a não-pluralidade conforme podemos ver na figura 4.

Figura 4. Encontro da isotopia geral

PLURALIDADE $\longrightarrow$ NÃO-PLURALIDADE $\longrightarrow$ UNICIDADE


Essa dimensão de unicidade, de afirmação e reconhecimento de si próprio, fica ainda mais nítida no formato cíclico da expressão “... Eu sou o que sou...", formando a isotopia da circularidade (unicidade).

Figura 5. Ciclo-unicidade

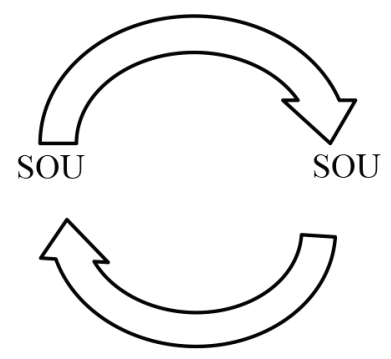

Apoiados na prática da embreagem e desembreagem da semiótica Greimasiana, ou seja, visualizando superficialmente o contexto e retornando ao escopo de análise, verificamos que o ideal de unicidade para as divindades da época era raro. Diferente de outras culturas que acreditavam na existência de vários deuses (politeísmo) - como o povo grego -, essa natureza de singularidade nasce com os israelitas, de certo modo, para fomentar a união do povo disperso, inseguro e impotente religiosamente.

Embasados nessa perspectiva, percebemos que S1 parte das parcialidades - isotopias de divinização - para a unicidade divina. As isotopias de divinização desaguam assim num único sentido máximo, a identidade consumada de S1. Essa identidade reflete a essência de Deus, a definição da personalidade e da totalidade do ser, absoluto e não contraditório, um verdadeiro axioma, que segundo Japiassú e Marcondes é "uma proposição evidente em si mesma" (2006, p. 23).

Figura 6. Isotopias de divinização

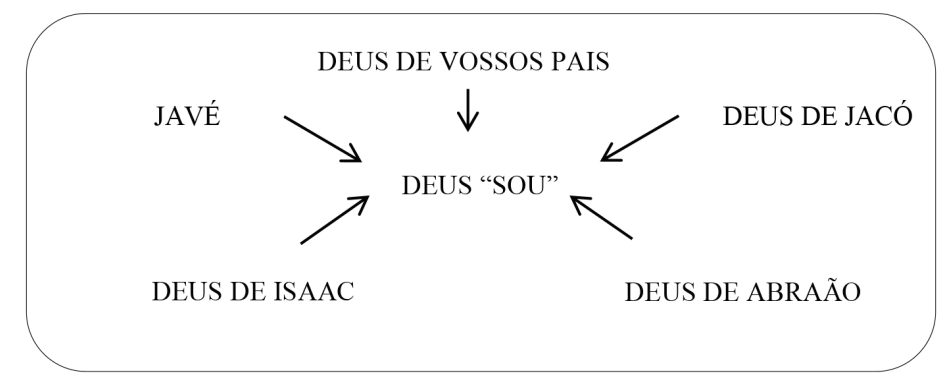


A condição absoluta desse sujeito divino representa nenhuma restrição ou mácula, o princípio da existência, pessoal e distinto do mundo. Ele é em si e por si, independentemente de qualquer outra coisa, possuindo em si mesmo sua própria razão de ser, não comportando nenhum limite e sendo considerado independentemente de toda relação com um outro (JAPIASSÚ MARCONDES (2006, p. 1).

Desse modo, Deus exibe-se perfeito, com uma identidade completa e acabada, alicerçada em todos os predicados inerentes e vitais à sua natureza, substancialmente idêntico a esta, ou seja, na sua plenitude, um gozo experimentado tão-somente por uma divindade. O bojo da totalidade desse Deus, oportunamente, enquadra-se como "aquilo que contém de tal forma o que contém que forma uma unidade" (JAPIASSÚ; MARCONDES 2006, p. 268).

Figura 7. Quadrado semiótico da veridicção e da identidade divina em oposição à humana

\begin{tabular}{|l|l|}
\hline \multicolumn{1}{|c|}{ SER } \\
IDENTIDADE DIVINA \\
(Eu Sou o Que Sou /ser/) \\
(Deus Pai, Criador) \\
(Onipresente, onisciente, \\
onipotente) (absoluto) \\
NÃO-PARECER
\end{tabular}

Podemos inferir que a isotopia geral do texto repercute na identidade consumada da divindade judaico cristã, acabada, perfeita, absoluta e totalizadora. Sua unicidade é resultado, portanto, da sua identidade definida em oposição à identidade parcializada, indefinida dos humanos que são sujeitos da busca constante de valores formadores de traços identitários em oposição a uma identidade já consumada.

\subsection{Sintaxe profunda}

A categoria semântica é / ser/ e / parecer/ uma vez que se trata da divindade, pois no/parecer/, deve ser interpretado o texto, quando Deus aparece e diz que a partir daquele momento ele deverá ser reconhecido como Javé (Iahweh, o Senhor). No /ser/, ele é o que é: Onipotente, Onisciente, 
Onipresente $=$ identidade absoluta, supremacia divina $=$ Sou $=$ Deus supremo.

O quadrado semiótico que segue, portanto, ao tomar-se toda a narrativa do livro do Êxodo é aquele da categoria semântica liberdade x opressão em que se nega a opressão, o escravagismo e afirma-se a liberdade, a libertação.

Figura 8. Quadrado semiótico da liberdade em oposição à opressão no PN da libertação

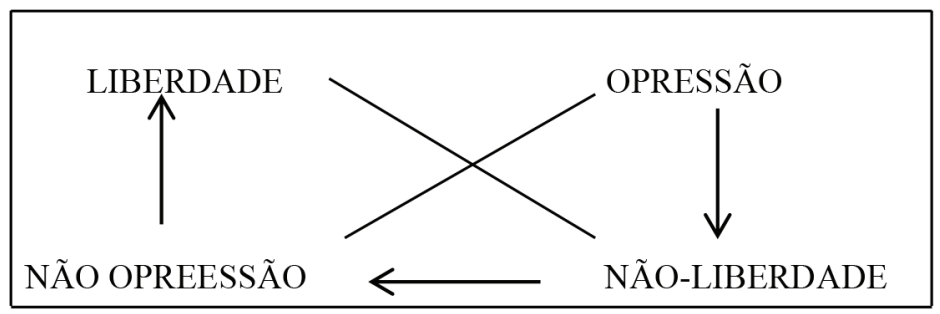

Porém, com referência ao corpus (contrato realizado entre Deus e Moisés) esse quadrado permanece virtualizado, pois só será realizado quando Moisés retirar o povo judeu do Egito. Esse PN (retirada do Egito) é uma performance modal se considerarmos como PN principal a chegada em Canaã (terra prometida) e fica, neste momento, virtualizado, porquanto nos propomos a analisar os três versículos do livro do êxodo. Moisés, neste caso fica sem sanção atribuída pela divindade que só o sancionaria de forma negativa no programa narrativo da entrada da terra prometida, posto que a vislumbrou, mas, não pôde entrar, no contexto total da narrativa do livro do Êxodo.

\section{Conclusão}

Partimos da proposta de mostrar-se, sem cunho especulativo ou religioso, a unicidade da divindade judaico cristã segundo fragmentos da narrativa do livro do Exxodo, defendendo a leitura objetiva do texto segundo os preceitos da semiótica da Escola de Paris. Nesta busca da objetividade mostramos que a leitura plural e ilusão referencial de Roland Barthes são termos que encontram equivalentes na semiótica de Greimas (2012), como os conceitos de pluri-isotopia e efeito de sentido. Há, de fato, leituras plurais na superfície textual, mas, na análise profunda estas convergem para uma 
isotopia principal, como é o caso da unicidade representada pela isotopia da circularidade da divindade em questão.

Em seguida destacamos o conceito de identidade do ponto de vista semiótico e psicanalítico com base nas reflexões de Waldir Beividas (2006) que detecta um problema para definir-se o termo e propõe um locus teórico a fim de atender sua sutileza semântica e densidade estrutural, por ser modalizada pelo aspecto volitivo, o que chama de um / querer/ tônico-tensivo, sugerindo que a identificação traduz uma posição semântica do sujeito vetorizada para a busca de uma identidade, cujo absolutismo seria impossível de ser alcançado. Concordamos com Beividas no que se refere à busca da identidade humana e discordamos em relação ao percurso da identidade divina, por esta estabelecer-se em nosso corpus como consumada, única e absoluta, conforme demonstramos.

No discorrer do estudo do corpus, procuramos mostrar que a semiótica traduz-se num instrumento eficaz para a interpretação e análise de narrativas bíblicas, como esta, de forma objetiva, por meio de sua sintaxe narrativa, semântica narrativa e a semântica discursiva, embora possam dar margem à subjetividade como produto da fé.

As relações entre os sujeitos acentuaram o caráter significativo máximo do texto, a identidade consumada da divindade judaica cristã que utiliza de meios variados para comprovar sua unicidade existencial, sua condição de absoluto e perfeito para Moisés a fim de promover a libertação do povo israelita. Em oposição à identidade divina consumada, encontramo-nos com a divindade humana em momento de construção.

Este artigo, portanto, procurou mostrar, em resumo, a aplicabilidade da teoria semiótica de forma objetiva em discursos que podem apresentar variedades de interpretação, como a visão espírita da Bíblia, a visão católica, a visão evangélica, etc, sem aquele caráter dogmático, mas, científico como ponto de partida para reflexões mais aprofundadas dos modos de ver a narrativa bíblica por parte das religiões existentes.

\section{Referências}

BARROS, Diana Luiz Pessoa. Teoria semiótica do texto. São Paulo: Ática, 1990.

BARTHES, R. Mitologias. Trad. de Rita Buongermino et al. 2.ed. Rio de Janeiro: DIFEL, 2006.

BEIVIDAS, W.; RAVANELLO, Tiago. Identidade e Identificação: entre semiótica e psicanálise. Alfa-Revista de Linguística, v. 50, p. 129-144, 2006. 
BÍBLIA de Estudo DEFESA DA FÉ. Questões reais. Respostas precisas. Fé solidificada. Rio de Janeiro, CPAD, Versão Revista e Corrigida. 2010.

BÍBLIA JUDAICA COMPLETA, o Tanakh [AT] e a B'rit Hadashau [NT]. Tradução do original para o inglês de David H. Stern. Tradução para português de Rogério Porterla e Celso Fernandes. Editora Vida, 1998 (inglês) e 2019 (português).

D’ÁILA, Nícia Ribas. Renartet Chanteclerc segundo a Teoria de Greimas. Revista Leopoldianum, n 47, volume XVI, 1990.

GREIMAS, Algirdas Julien; COURTÉS, Joseph. Dicionário de Semiótica. São Paulo: Editora Cultrix, 1973.

Dicionário de Semiótica. 2. ed., São Paulo: Contexto, 2012.

JAPIASSÚ, Hilton; MARCONDES, Danilo. Dicionário básico de filosofia. Rio de Janeiro: Zahar, 2006.

SANTOS, Valdenildo dos. Percurso Semiótico do Actante Sujeito John, the god-man. Tese de Doutorado - Universidade Estadual Paulista "Julio de Mesquita Filho". Assis, SP, 2001, 227p.

ZILBERBERG, Claude. Elementos de Semiótica Tensiva. São Paulo: Edusp, 2006.

Submetido em: 22-8-2015

Aceito em: 7-4-2017 